\title{
Association of Men's Awareness of Danger Sign of Obstetric Complication and Male Involvement's in Birth Preparedness Practices at South Ethiopia
}

\author{
Alemu Tamiso, Behailu Merdekios, Marelign Tilahun \\ Department of Public Health, College of Medicine and Health Science, Arba Minch University \\ Arba Minch, South Ethiopia
}

\begin{tabular}{l} 
Article Info \\
\hline Article history: \\
Received Jan 18, 2015 \\
Revised Jan 30, 2015 \\
Accepted Feb 12, 2015 \\
\hline
\end{tabular}

Keyword:

Birth Preparedness Practice

Chencha District

Men awareness

Obstetric Danger Sign

Southern Ethiopia

\begin{abstract}
The Ethiopian Demographic and Health Survey (EDHS) indicate that maternal mortality in Ethiopia is one of the highest in the world. This death toll can be prevented partially through increasing awareness of danger sign of obstetric complications and birth preparedness practices for mother, husbands and other family members. Community based cross sectional study was done. Adult males with a wife or partner who had been through childbirth in the preceding 36 months were included in the study. Data was collected by pretested structured questionnaires and multi stage cluster sampling was used to reach 845 samples. Collected data was cleaned and entered in to Epi Info 7 and exported to SPSS (IBM-20) for further analysis. Hierarchical logistic regression model and adjusted odds ratio with 95\% confident interval were used to show association between men awareness and birth preparedness practices. The total numbers of men interviewed were 836 that makes response rate of $98.9 \%$. Severe abdominal pain (87\%) was the most recognized danger sign during pregnancy and $17.9 \%$ men involved in saving money. Forty two point two percent $(42.2 \%)$ of men had awareness of danger sign and $9.4 \%$ (95\% CI: $(7.42,11.4)$ of men involved in birth preparedness practice. Strong association between men awareness of danger sign of obstetric complications and involvements in birth preparedness practices persisted after adjusting for probable confounders. The prevalence of men awareness of danger sign \& involvement in birth preparedness practice was very low.
\end{abstract}

Copyright (C) 2015 Institute of Advanced Engineering and Science. All rights reserved.

\section{Corresponding Author:}

Alemu Tamiso,

Department Public Health,

College of Medicine and Health Sciences,

Arba Minch University, Southern Ethiopia.

Email: alemutamiso@yahoo.com

\section{INTRODUCTION}

Male partner involvement in women's sexual and reproductive health as well as maternal and child health care has attracted considerable attention since the International Conference was held on Population and Development (ICPD) in Cairo, 1994 [1] and the 4th World Conference on Women in Beijing, [2] which were on women's health and the need to have men more involved in the promotion of sexual and reproductive health. Both conferences emphasized men's shared responsibility and active partnership in sexual and reproductive health and promotion of gender equality [1],[2].

Maternal death arises from pregnancy, childbirth or postpartum complications, but their occurrences could be reduced by imparting knowledge about obstetric complication and making birth preparedness plans for pregnant women, their partners and families as well. [3] Antenatal care, birth preparedness plans and 
complication-readiness are crucial for timely access to skilled maternal and neonatal services. These factors promote active preparation and decision-making for delivery [4].

The key elements of the birth plan includes, a plan for skilled birth attendants, place of delivery, and arrangement of money for transport or other costs [5]. The birth plan is a very important strategy in developing countries where obstetric services are weak and thus contribute significantly to maternal and neonatal morbidity and mortality [6]. A husband at antenatal clinic is rare in many communities and it is unthinkable to find men accompanying their partners during Ante natal care and delivery [7].

However, men hold social and economic power and have tremendous control over their partners, especially in developing countries [8],[9]. They decide the timing and conditions of sexual relations, family size, and utilization of available health care services of their spouses [8],[10]. Strategies for involving men in maternal health services should aim at raising their awareness about emergency obstetric complication, and engaging them in birth plans and complication readiness [5]. Men awareness on reproductive issues enables them to support their mates to utilize obstetric services and eventually would help couples adequately prepare for birth complications [11]. This would lead to a reduction in all three phases of delay: delay in the decision to seek care; delay in reaching care; and finally, delay in receiving care. The male partner can play a crucial role especially in the first and second phases of delay in developing countries and thereby positively impact birth outcomes [11].

Ethiopia has culturally dynamic and patriarchic societies. The low status of women, socio-cultural barriers to seeking care: women's mobility, ability to command resources, decision-making abilities, beliefs and practices surrounding childbirth and delivery has great impact on women's health. Most of the reproductive health programs fail to address these factors in Ethiopia [10]. Increasing male awareness of danger sign of obstetric complication and involvements in birth preparedness practices is necessary in culturally dynamic societies like Ethiopia to improve the women's health and reduce maternal mortality.

Therefore this study tried to assess the association between men's awareness of danger sign of obstetric complications and involvement in birth preparedness practices at Chencha district of southern Ethiopia.

\section{RESEARCH METHOD}

The study was conducted in Chencha district of Gamo Gofa Zone of south Ethiopia. It is located 562 $\mathrm{Km}$ south west of the capital of Ethiopia, Addis Ababa, and $332 \mathrm{Km}$ south west of Regional capital, Hawassa, with total population of 137,196 and estimated women with child bearing age of 31,966. The district has 50 Kebeles (districts' small administrative unit), five urban and 45 rural with 27,999 households until the end of 2013. It has one district hospital, six health centers and 50 health posts. The study was conducted from April to May 2014. Community based cross sectional study was implemented.

All adult male with a wife or partner who lives in the district and all male in the selected kebeles (districts' small administrative unit) with a wife or partner who had been through childbirth in the preceding 36 months were source and study population respectively.

The required sample size was determined by using StatCalc program of Epi Info version 7 statistical package with $5 \%$ desired precision, $\mathrm{Z}$ score corresponding to $95 \%$ confidence interval, $50 \%$ male awareness on danger sign of obstetric complication (due to absence of previous study on men awareness), ten percent of non-response rate and design effect of two resulting in a total of 845 study participants.

Multistage stage cluster sampling technique was used to reach household level. The district was divided in to two; urban and rural area, then nine kebeles (small administrative unit) from rural and one kebele from urban were selected by simple random sampling, considering the assumption of scholar named Hosmer and Leme-show( 20\% suggestion of minimum sample size). Proportional to size allocation technique was used to allocate the sample to each kebeles, and the kebeles were divided into different clusters based on 'Goti' (small-villages in kebele) and number of participant in each cluster were enumerated. Based on the allocated sample size, $\mathrm{k}$ clusters were selected from each kebele and total participants in each cluster were asked until we collected the adequate sample from each kebele.

\section{Data collection}

Data was collected by using face to face interview techniques using pretested and structured questionnaires. The information collected was about socio-demographic characteristics (maternal age, paternal age, marital status, ethnicity, religion, residence and educational status of woman/husband), household characteristics (wealth index/economic status, family size, and time to reach health facility), reproductive characteristics (gravidity, parity, and place of delivery), men awareness on danger signs of obstetric complications at three stages and different components of birth preparedness practices. The questionnaire was first prepared in English and translated to Amharic (the national language) and then back 
to English by two different language experts to check for consistency and clarity. Ten diploma nurses were hired as data collectors \& supervised by principal investigator when conducting home to home visit after three days of training on basic skills of interview, ways of obtaining verbal consent and objective of the study.

\section{Data quality assurances}

To maintain the quality of data, the collectors were trained, Pre-test was done on 43 individuals ( $5 \%$ of the study participants) out of the study area with similar population in order to assess the validity of the questionnaires and correction was made after preliminary data analysis. Definition of concepts and terms were made clear to participants with a common language of the district to avoid ambiguity. the supervisor underwent on-site supervision during data collection period and reviewed all the filled questionnaires during the next morning of each data collection so as to identify incomplete and incoherent responses. Data was cleaned by performing frequencies and cross tabulation for all categorical variables by using SPSS (IBM-20).

\section{Data processing and analysis}

Each completed questionnaires was checked manually for completeness before data entry. The data was coded and entered into Epi Info version 7 and cleaned up to check accuracy and consistency was made and any error identified was corrected. Final data was exported to SPSS (IBM-20) for further clean up and analysis. Frequency, proportion, mean, and standard deviation were used to summarize results and table and figures were carried out to presents important findings. Hierarchical logistic regression model was fitted to know association between explanatory and outcome variables. Crude odd ratio and Adjusted odds ratio with $95 \%$ CI was used to determine the presence and strength of association between men's awareness of danger signs and involvement in birth preparedness practices.

\section{Ethical consideration}

Ethical clearance for the study was obtained from the Institutional Ethical Review Board of College of medicine and health Sciences of Arba Minch University, permission letter was taken from Chencha district health offices, and informed verbal consent was taken from individual participant, since most of them were unable to read and write. No form of identifiers was included in the questionnaires to maintain confidentiality. Participation was voluntary and participants were informed that they could withdraw from the study at any stage if they desired, without any intimidation. At the end of interview information was given about danger signs of obstetric complication at three stages (during pregnancy, labor and child birth, and postpartum period). In addition participants were informed about the importance of involvement in birth preparedness and components of birth preparedness plan.

\section{RESULTS AND ANALYSIS}

\section{Socio-demographic and Economic characteristics}

The total numbers of men interviewed were 836 making the response rate of $98.9 \%$. Mean and standard deviation of age of respondents were 37.4(range: 30-40) and \pm 8.95 respectively. The majority of respondents were married (97.8\%) and farmer (42.5\%). Almost all (97.8\%) of the husbands were Gamo by ethnicity and five hundred eight (60.8\%) were orthodox by religion. Mean age of wives of respondents' were $34.5 \pm 10.9$. Majority (74.2\%) of wives of respondents was house wives by occupation and had not attended any level of education (54.1\%). Regarding economic status; twenty point three percent (170) were constituted in second wealth quintal (as Table 1).

\section{Reproductive characteristics}

Mean (average) time taken to reach health facility for delivery services is $40.5 \pm 34.9$. More than three fourth (93.1\%) of household have had two or more children. Majority (60.6\%) of household use local transportation/Kareza to provide pregnant women in labour to health facility and almost all $(96.3 \%)$ participants knew where to go if labour commence to their wife's. Four hundred ninety seven (59.6\%)of the respondents' wife has driven birth at home and the rest $41.6 \%$ at different public health facilities such as public hospital(16.5\%), public health center (16.4\%) and health posts(7.7\%) in the past three years. 
Table 1.Socio-demographic and economic characteristics of respondents, at Chencha district, 2014

\begin{tabular}{|c|c|c|}
\hline Variables & Frequency & $\%$ \\
\hline \multicolumn{3}{|l|}{ Residence } \\
\hline Rural & 610 & 73 \\
\hline Urban & 226 & 27 \\
\hline Total & 836 & 100 \\
\hline \multicolumn{3}{|l|}{ Marital status } \\
\hline Married & 818 & 97.8 \\
\hline Widowed & 7 & 0.8 \\
\hline Separated & 11 & 1.3 \\
\hline \multicolumn{3}{|l|}{ Religion } \\
\hline Protestant & 326 & 39.0 \\
\hline Orthodox & 508 & 60.8 \\
\hline Catholic & 2 & 0.2 \\
\hline \multicolumn{3}{|l|}{ Ethnic group } \\
\hline Gamo & 833 & 99.6 \\
\hline Others( Wolaita) & 3 & 0.4 \\
\hline \multicolumn{3}{|l|}{ Maternal education } \\
\hline No education & 452 & 54.1 \\
\hline Primary education & 206 & 24.6 \\
\hline Secondary education & 112 & 13.4 \\
\hline Above secondary education & 66 & 7.9 \\
\hline \multicolumn{3}{|l|}{ Occupational status of Respondents } \\
\hline Farmer & 355 & 42.5 \\
\hline Weaver & 229 & 27.4 \\
\hline Merchant & 64 & 7.7 \\
\hline Government employee & 108 & 12.9 \\
\hline Private gainful work & 49 & 5.9 \\
\hline Without gain full work & 31 & 3.7 \\
\hline \multicolumn{3}{|l|}{ Age of respondents } \\
\hline$<=19$ & 5 & 0.6 \\
\hline $20-30$ & 171 & 20.5 \\
\hline $31-40$ & 378 & 45.2 \\
\hline $41-50$ & 164 & 19.6 \\
\hline$>50$ & 37 & 4.4 \\
\hline \multicolumn{3}{|l|}{ Paternal education } \\
\hline No education & 330 & 39.5 \\
\hline Primary education & 235 & 28.1 \\
\hline Secondary-education & 151 & 18.1 \\
\hline Above secondary education & 120 & 14.4 \\
\hline \multicolumn{3}{|l|}{ Occupational status of wife } \\
\hline House wife & 620 & 74.2 \\
\hline Farmer & 70 & 8.4 \\
\hline Weaver & 10 & 1.2 \\
\hline Governments employee & 51 & 6.1 \\
\hline Others(merchant) & 85 & 10.2 \\
\hline \multicolumn{3}{|l|}{ Wealth index quintal } \\
\hline Lowest & 167 & 20.1 \\
\hline Second & 170 & 20.3 \\
\hline Middle & 164 & 19.6 \\
\hline Fourth & 167 & 20.0 \\
\hline Highest & 168 & 20.0 \\
\hline
\end{tabular}

\section{Men awareness of obstetric danger sign during pregnancy, labour and after child birth}

Three hundred thirty six [(42.2\%, 95\% CI: $(\mathbf{0 . 3 9}, \mathbf{0 . 4 6})]$ of the men knew danger sign of obstetric complications which is measured by above average mean score at three stages. The percentage of men who knew vaginal bleeding related to pregnancy (34\%), in relation to delivery $(60.4 \%)$ and in relation to postpartum period were $32.2 \%$. Severe abdominal pain (87\%) was the most recognized danger sign and water breaks before labour (1.2\%) was the list mentioned danger sign during pregnancy. Severe vaginal bleeding was the most recognized sign during labour and child birth and after delivery by $32.2 \%$ and $60.4 \%$ respectively. Loss of consciousness was the list recognized sign during labour (13\%) and after child birth (2.8\%). Prolonged labor was known by only $21.4 \%$ of men, while retained placenta was recognized by $19.7 \%$ (as Table 2). 
Table 2. Men awareness of obstetric danger sign during pregnancy, labour and after child birth, 2014

\begin{tabular}{|c|c|c|c|c|c|c|}
\hline \multirow{2}{*}{ Obstetric danger sign } & \multicolumn{2}{|c|}{ During pregnancy } & \multicolumn{2}{|c|}{ During labor and child birth } & \multicolumn{2}{|c|}{ After child birth(postpartum) } \\
\hline & $\mathbf{n}$ & $\%$ & n & $\%$ & $\mathbf{n}$ & $\%$ \\
\hline \multicolumn{7}{|l|}{ Severe vaginal bleeding } \\
\hline Yes & 284 & 34.0 & 505 & 60.4 & 269 & 32.2 \\
\hline No & 552 & 66.0 & 331 & 39.6 & 567 & 67.8 \\
\hline \multicolumn{7}{|l|}{ High Grade Fever } \\
\hline Yes & 108 & 12.9 & 191 & 22.8 & 109 & 13.0 \\
\hline No & 728 & 87.1 & 645 & 77.2 & 727 & 87.0 \\
\hline \multicolumn{7}{|l|}{ Loss of Consciousness } \\
\hline Yes & 51 & 6.1 & 109 & 13.0 & 23 & 2.8 \\
\hline No & 785 & 93.9 & 727 & 87.0 & 813 & 97.2 \\
\hline \multicolumn{7}{|l|}{ Prolonged labor } \\
\hline Yes & & & 179 & 21.4 & & \\
\hline No & & & 657 & 78.6 & & \\
\hline \multicolumn{7}{|l|}{ Retained placenta } \\
\hline Yes & & & 165 & 19.7 & & \\
\hline No & & & 671 & 80.3 & & \\
\hline \multicolumn{7}{|l|}{ Severe Headache } \\
\hline Yes & 120 & 14.4 & & & 52 & 6.2 \\
\hline No & 716 & 85.6 & & & 784 & 93.8 \\
\hline \multicolumn{7}{|l|}{ Blurring of Vision } \\
\hline Yes & 155 & 18.5 & & & 120 & 14.4 \\
\hline No & 681 & 81.5 & & & 716 & 85.6 \\
\hline \multicolumn{7}{|l|}{ Convulsions } \\
\hline Yes & 52 & 6.2 & & & 42 & 5.0 \\
\hline No & 784 & 93.8 & & & 794 & 95.0 \\
\hline \multicolumn{7}{|l|}{ Swollen Hands/Face } \\
\hline Yes & 81 & 9.7 & & & 43 & 5.1 \\
\hline No & 755 & 90.3 & & & 793 & 94.9 \\
\hline \multicolumn{7}{|l|}{ Difficulty of Breathing } \\
\hline Yes & 35 & 4.2 & & & 42 & 5.0 \\
\hline No & 801 & 95.8 & & & 794 & 95.0 \\
\hline \multicolumn{7}{|l|}{ Severe Weakness } \\
\hline Yes & 173 & 20.7 & & & 211 & 25.2 \\
\hline No & 663 & 79.3 & & & 625 & 74.8 \\
\hline \multicolumn{7}{|l|}{ Severe Abdominal Pain } \\
\hline Yes & 107 & 87.2 & & & & \\
\hline No & 729 & 12.8 & & & & \\
\hline \multicolumn{7}{|l|}{ Accelerated/ Reduced Foetal } \\
\hline \multicolumn{7}{|l|}{ Movement } \\
\hline $\begin{array}{l}\text { Yes } \\
\text { No }\end{array}$ & 685 & 81.9 & & & & \\
\hline \multicolumn{7}{|l|}{ Water Breaks without Labor } \\
\hline Yes & 10 & 1.2 & & & & \\
\hline \multirow{2}{*}{\multicolumn{7}{|c|}{ Malodorous Vaginal Discharge }} \\
\hline & & & & & & \\
\hline Yes & & & & & 35 & 4.2 \\
\hline No & & & & & 801 & 95.8 \\
\hline
\end{tabular}

Male involvements in birth preparedness practices

The prevalence of men involvements in birth preparedness practice was 9.4 \%( 95\%CI: 7.42-11.4) as Figure 1. Among them seventeen point nine percent of men involve in saving money and only zero point five percent of respondents involve in identification of skilled health professional as Figure 2.

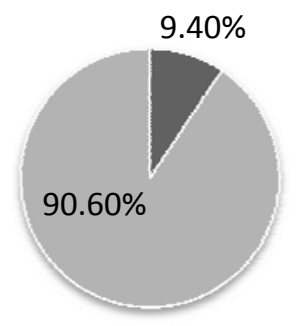

Male involvement in
birth prepardness
practices (Yes)
Male involvement in
birth prepardness
practices (No)

Figure 1. prevalence of male involvements in birth preparedness practice at Chencha district of southern Ethiopia, 2014 


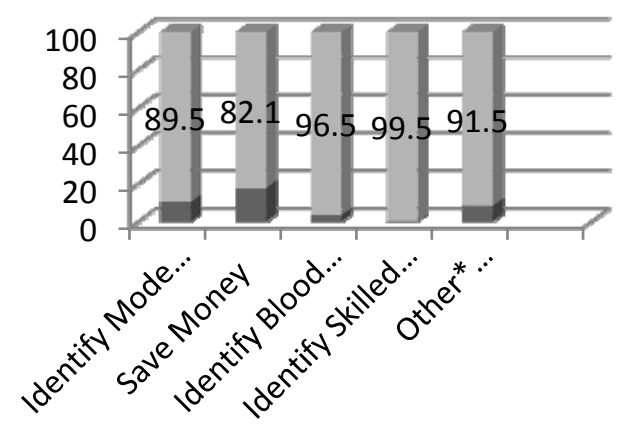

Involvement in birth prepardness No

Involvement in birth prepardness Yes

Figure 2. Frequency of men involvements in birth preparedness practice at Chencha district of Gamo-Gofa zone

\section{Association between men awareness of danger sign of obstetric complication and involvements in birth preparedness practice}

The results show a clear association between men awareness of danger signs of obstetric complication and involvement in birth preparedness practice at the district. The association remained statistically significant even after controlling for possible confounding of residence, wealth index, educational status and occupational status of women. Thus respondent who had awareness of danger signs of obstetric complication was two times [(AOR: 1.91, 95\% CI: (1.06, 3.41)] more likely to be involved in birth preparedness practice than respondents who had no awareness of danger signs of obstetric complication as Table 3.

Table 3. Association (Odds Ratio, 95\% CI) between men awareness on danger sign of obstetric complication and birth preparedness: Hierarchical logistic regression analysis

\begin{tabular}{|c|c|c|c|c|}
\hline $\begin{array}{c}\text { Male involvements in } \\
\text { Birth preparedness } \\
\text { practice }\end{array}$ & $\begin{array}{l}\text { Crude odd } \\
\text { ratio }\end{array}$ & $\begin{array}{l}\text { Model } 1 \\
\text { (Adjusted for } \\
\text { Residences) }\end{array}$ & $\begin{array}{c}\text { Model } 2 \\
\text { (Adjusted for } \\
\text { residence, and } \\
\text { Wealth index) }\end{array}$ & $\begin{array}{c}\text { Model } 3 \\
\text { (Adjusted for residence, } \\
\text { Wealth index, education } \\
\text { and occupational status) }\end{array}$ \\
\hline \multicolumn{5}{|l|}{ Men awareness } \\
\hline Had awareness & $1.79(1.12,2.8)$ & $2.58(1.54,4.30)$ & $2.26(1.30,3.92)$ & $1.91(1.07,3.41)^{*}$ \\
\hline Had no awareness & 1 & 1 & 1 & 1 \\
\hline \multicolumn{5}{|l|}{ Residences } \\
\hline Rural & - & $0.31(0.19,0.54)$ & $0.31(0.18,0.54)$ & $0.27(0.15,0.49)^{* *}$ \\
\hline urban & & 1 & 1 & 1 \\
\hline \multicolumn{5}{|l|}{ Wealth index quintal } \\
\hline Lowest & & & $0.12(0.02,0.99)$ & $0.19(0.23,1.64)$ \\
\hline Second & - & & $3.37(1.55,7.32)$ & $4.38(1.93,9.92)^{* *}$ \\
\hline Middle & & - & $5.29(2.44,11.5)$ & $7.04(3.01,16.5)^{* *}$ \\
\hline Fourth & & & $0.86(0.29,2.49)$ & $1.21(0.39,3.77)$ \\
\hline Highest & & & 1 & 1 \\
\hline \multicolumn{5}{|l|}{ Paternal education } \\
\hline $\begin{array}{l}\text { No education } \\
\text { Primary education } \\
\text { Secondary-education } \\
\text { Above secondary } \\
\text { education }\end{array}$ & - & - & - & $\begin{array}{c}0.77(0.28,2.13) \\
1.71(0.68,4.28) \\
4.61(1.91,11.1)^{* *} \\
1\end{array}$ \\
\hline \multicolumn{5}{|l|}{ Maternal occupation } \\
\hline Housewife & & & & 1 \\
\hline Farmer & & & & $0.23(0.061,0.88)$ \\
\hline Weaver & - & - & - & $1.06(0.10,10.3)$ \\
\hline Government employ & & & & $0.54(0.14,2.02)$ \\
\hline Other(merchant) & & & & $0.79(0.35,1.78)$ \\
\hline
\end{tabular}

Note: P-value: $*<0.05 \quad * * \mathbf{p}<0.001$

\section{DISCUSSION}

Although research has not previously assessed men's awareness of obstetric danger signs and association between men awareness of obstetric danger signs and involvement in birth preparedness practice 
in Ethiopia, this study potentially suggest that men would have an equal understanding compared to women. Based on this assumption, this study used study done on women and men to discuss the results.

The finding of this study revealed that the level of men awareness of danger sign of obstetric complication was [42.2\%, (95\%CI (39\%, 46\%)] which was assessed by average mean score, this is lower than findings of the study done among men in rural area of Kenya, and Tanzania, [9],[12] and higher than the study conducted in Egypt, Alexandria and study in Uganda [13],[14]. The low awareness could be explained by poor counseling of danger signs among those who attended antenatal clinics as compared to study done in Tanzania, that the majority of the study subjects attended antenatal clinics and counseled for danger sign. [12] The higher awareness in this study might be due to Ethiopian Governments emphasis of on health extension program, that aware the majority of men about danger sign of obstetric complication. [10],[15],[16] The discrepancy is also due to difference in the setting, sample size and measurements tool of awareness among participants, that this study utilized average mean score from three phases(pregnancy, childbirth and postpartum) and others used mentioning of two or three danger signs of obstetric complications.

The magnitude of men involvements in birth preparedness practices of 9.4\% estimated in our study appears to be higher than what was reported from Kenya 7\%[17]. But lower than (20\%- 22\%), 44.3\%, 48\% reported in studies from Ethiopia, Uganda and India respectively [18]-[21]. Low level of involvement in birth preparedness might be due to low level of economic status, in the district, which in turn hampers husbands not to involve in the birth preparedness practices, particularly involving in saving money. In addition this study showed, males give due emphasis to food and cloth preparation for upcoming baby and mother than preparing for transportation and saving money, this might also due to one way ambulance service that has been provided freely for the laboring mother and delivery services in the health center [22].

The study also showed the significant association between men's awareness of danger sign of obstetric complication and involvement in birth preparedness practice. Accordingly male who had awareness of danger sign of obstetric complication was two times more likely involved in birth preparedness practice than male who had no awareness of danger sign. This was evidenced by the study done in Uganda that women awareness of danger sign predicts the level of birth preparedness practices [23]. This might be due to on the assumption that knowledge of danger signs leads to greater anticipation and preparation to mitigate effects of pregnancy and childbirth complications by reducing the first two delays and the third delay if health facilities are prepared to address obstetric complications.

Furthermore educational status, economic status which was measured by wealth index quintal and place of residence had significant effect on male involvements in birth preparedness practices, but occupational status has no significant effect on male involvement in birth preparedness practices.

It is difficult, however to compare our study findings with those from others as the measures used to determine birth preparedness had some variations and there is also differences in sex. Nevertheless, the underlying principles regarding birth preparedness are the same and the methods used to study birth preparedness was the same [24]. It is possible that there may have been different degrees of recall bias between men who did have wife who gave birth before two years and within two years. This may introduce misclassification bias, resulting in positive/negative association. Confounding was controlled in the analysis by stepwise hierarchical logistic regression model. Possible confounders were introduced into the level and they did not have significant effect on the association between men awareness of danger signs and involvement in birth preparedness practices.

\section{CONCLUSION}

Our study showed low level of awareness of obstetric danger signs and involvement in birth preparedness practice among men in Chencha district of southern Ethiopia. The study also demonstrated strong association between men awareness of dangers signs of obstetric complication and men involvements in birth preparedness. It is of paramount importance if husbands are able to recognize the danger signs of obstetric complications which are an indication that urgent emergency care needs to be sought from skilled attendants and which in turn increase their involvement in birth preparedness practice.

\section{ACKNOWLEDGEMENTS}

The authors are very grateful to Chencha District health office, for its administrative and technical assistance. Research directorate offices of Arba Minch University deserves especial acknowledgement and Essayas Delese acknowledged for his support with supervision of data collection. 


\section{REFERENCES}

[1] McIntosh CA., Finkle JL.,“The Cairo conference on population and development: A new paradigm?”,Population and development review,pp. 223-60, 1995.

[2] Larson EL., "United Nations Fourth World Conference on Women: Action for Equality, Development, and Peace (Beijing, China: September 1995)”,Emory Int'l L Rev,vol. 10, pp. 695, 1996.

[3] WHO/UNFPA/UNICEF/World Bank, “Statement on Reduction of Maternal Mortality”, Geneva, Switzerland: WHO, 1999.

[4] McPherson RA., Khadka N., Moore JM., Sharma M.,“Are birth-preparedness programmes effective? Results from a field trial in Siraha district, Nepal”,Journal of Health Population and Nutrition,vol/issue: 24(4), pp. 479-88, 2006.

[5] JHPIEGO,"Maternal and Neonatal health (MNH) program, birth preparedness and complication readiness: A matrix of shared responsibilities”,Maternal and Neonatal Health,pp. 23-31, 2001.

[6] Drennan M.,"Reproductive health: New perspectives on men's participation”,Population Reports Series J, pp. 46. Baltimore: Johns Hopkins University, Population Information Programme, 1998.

[7] Babalola S., Fatusi A.,"Determinants of use of maternal health services in Nigeria-looking beyond individual and household factors”,BMC Pregnancy \& Childbirth,vol. 9, pp. 43, 2009.

[8] Iliyasu Z., Abubakar IS., Galadanci HS., Aliyu MH.,"Birth preparedness, complication readiness and fathers' participation in maternity care in a northern Nigerian community”, African Journal of Reproductive Health,vol/issue: 14(1), 2010.

[9] Dunn A., Haque S., Innes M.,“Rural Kenyan men’s awareness of danger signs of obstetric complications”,Pan African Medical Journal,vol. 10, 2011.

[10] Tesfaye S.,"A national scoping exercise and strategic recommendations for working with individuals, families and communities to improve maternal and neonatal health in Ethiopia (editorial)”,Ethiop J Health Dev.,vol/issue: 24(Special Issue 1), pp. 89-91, 2010.

[11] Odimegwu C., Adewuyi A., Odebiyi T., Aina B., Adesina Y., Olatubara O., Eniola F., “Men's role in emergency obstetric care in Osun state of Nigeria”,Afr J Reprod Health,vol/issue: 9(3), pp. 59-71, 2005.

[12] Pembe AB., Urassa DP., Carlstedt A., Lindmark G., Nyström L., Darj E.,"Rural Tanzanian women's awareness of danger signs of obstetric complications”,BMC Pregnancy and Childbirth,vol/issue: 9(1), pp. 12, 2009.

[13] Rashad WA., Essa RM.,"Women’s Awareness of Danger Signs of Obstetrics Complications”,Journal of American Science,vol/issue: 6(11), 2010.

[14] Kabakyenga JK., Östergren PO., Turyakira E., Pettersson KO.,“Knowledge of obstetric danger signs and birth preparedness practices among women in rural Uganda”, Reproductive health,vol/issue: 8(1), pp. 33, 2011.

[15] Federal Ministry of Health (FMOH), Ethiopia,"Health and Health Related Indicators: 2006/7”, Addis Ababa, Ethiopia: FMOH, 2007.

[16] Wilder J.,“Ethiopias Health Extension Program: Pathfinder Internationals support 2003-2007”, 2008.

[17] Mutiso SM., Qureshi Z., Kinuthia J.,“Birth preparedness among antenatal clients”,East Afr Med J,vol/issue: 85(6), pp. 275-283, 2008.

[18] Hailu M., Gebremariam A., Alemseged F., Deribe K.,"Birth preparedness and complication readiness among pregnant women in Southern Ethiopia”,PloS one,vol/issue: 6(6), pp. e21432, 2011.

[19] Hiluf M., Fantahun M.,"Birth preparedness and complication readiness among women in Adigrat town, north Ethiopia”,Ethiopian Journal of Health Development,vol/issue: 22(1), pp. 14-20, 2008.

[20] Agarwal S., Sethi V., Srivastava K., Jha PK., Baqui AH.,"Birth preparedness and complication readiness among slum women in Indore city, India”,Journal of health, population, and nutrition,vol/issue: 28(4), pp. 383, 2010.

[21] Kakaire O., Kaye DK., Osinde MO.,"Male involvement in birth preparedness and complication readiness for emergency obstetric referrals in rural Uganda”,Reproductive health,vol/issue: 8(12), pp. 1-7, 2011.

[22] FMOH,“Ethiopia five year Health Sector Development Program IV (2010/11 - 2014/15)”, Addis Ababa: Federal Ministry of health, 2010.

[23] Mbalinda SN., Nakimuli A., Kakaire O., Osinde MO., Kakande N., Kaye DK.,“Does knowledge of danger signs of pregnancy predict birth preparedness? A critique of the evidence from women admitted with pregnancy complications”,Health Research Policy and Systems,vol/issue: 12(1), pp. 60, 2014.

[24] Kakaire, et al.,"Male involvement in birth preparedness and complication readiness for emergency obstetric referrals in rural Uganda”,Reproductive Health,vol. 8, pp. 12, 2011. 